\title{
Clinical pharmacokinetics of ketoprofen enantiomers in wild type of Cyp 2c8 and Cyp 2c9 patients with rheumatoid arthritis
}

\author{
Franciszek Główka • Marta Karaźniewicz-Łada • \\ Edmund Grześkowiak • Dominika Rogozinska • \\ Wojciech Romanowski
}

Received: 3 February 2011 / Accepted: 11 April 2011/Published online: 24 April 2011

(c) The Author(s) 2011. This article is published with open access at Springerlink.com

\begin{abstract}
Pharmacokinetics of ketoprofen (KTP) enantiomers has been studied in patients with rheumatoid arthritis (RA) following administration of a single oral dose of $100 \mathrm{mg}$ rac-KTP during multidrug therapy taking into consideration the genotype of RA patients Concentrations of $(-)-R$ and (+)-S enantiomers of KTP in plasma, urine and synovial fluid samples were determined using a validated HPCE method. The genotype of the patients was analyzed using PCR-RFLP method to determine the polymorphic variants of genes coding CYP2C8 and CYP2C9 isoenzymes. The levels of KTP enantiomers in synovial fluid at $4 \mathrm{~h}$ following administration were insignificantly greater [(-)$R=1.34 \pm 0.91 \mathrm{mg} / \mathrm{L} ;(+)-S=1.38 \pm 0.91 \mathrm{mg} / \mathrm{L}]$ than in plasma $[(-)-R=1.15 \pm 0.95 \mathrm{mg} / \mathrm{L} ;(+)-S=1.22 \pm$ $0.95 \mathrm{mg} / \mathrm{L}]$. The values of $\mathrm{AUC}_{0-\infty}$ were $11.89 \pm 5.00$ and $10.92 \pm 4.10 \mathrm{mg} \mathrm{h} / \mathrm{L}$ for (-)- $R$ and (+)- $S$ enantiomer, respectively, and were lower compared with data obtained in healthy volunteers following administration of the same dose of rac-KTP. But, no statistically significant differences were observed also for $C_{\max }, \mathrm{Cl}, V_{\mathrm{d}}, t_{0.5}$ and MRT of KTP enantiomers. The total percentage of unchanged KTP eliminated with urine of RA patients was in the range of $30-50 \%$ of
\end{abstract}

F. Główka $(\bowtie) \cdot$ M. Karaźniewicz-Łada · D. Rogozinska Depatment of Physical Pharmacy and Pharmacokinetics, Poznan University of Medical Sciences, 6 Święcickiego Street, 60-781 Poznań, Poland

e-mail: glowka@ump.edu.pl

E. Grześkowiak

Department of Clinical Pharmacy and Biopharmacy,

Poznan University of Medical Sciences,

14 Św. Marii Magdaleny Street, 61-861 Poznań, Poland

W. Romanowski

Poznan Rheumatology Center in Śrem, 95 Mickiewicza Street, 63-100 Śrem, Poland the administered dose. Though RA patients represented the same wild genotype, quite significant variabilities $\left(\mathrm{Cl}_{(-)-R}=2.37-13.50 \mathrm{~L} / \mathrm{h}\right.$ and $\left.\mathrm{Cl}_{(+)-S}=2.44-9.90 \mathrm{~L} / \mathrm{h}\right)$ existed in the pharmacokinetics parameters of KTP. We concluded that KTP data obtained from healthy volunteers cannot be sufficient to predict disposition of KTP enantiomers in RA patients, especially when undergoing long-term multidrug therapy.

Keywords Stereoselective pharmacokinetics .

Bioavailability · Cytochrome P450 - Pharmacogenetics . Capillary zone electrophoresis

\section{Introduction}

Ketoprofen (KTP) belongs to the group of 2-arylpropionic acid (2-APA) derivatives and is one of the most commonly used non-steroidal anti-inflammatory drugs (NSAIDs). Generally, it is prescribed for the treatment of inflammation and pain caused by rheumatoid arthritis (RA) and osteoarthritis. The 2-APA propionic acid side chain possesses an asymmetric $\alpha$-carbon and therefore KTP occurs as (-)- $R$ and (+)- $S$ enantiomers. Its therapeutic activity is associated with inhibition of the cyclooxygenase (COX-1, COX-2) with a reduction of prostaglandin production such as $\mathrm{PGE}_{2}, \mathrm{PGF}_{2 \alpha}$ in tissue (Baek et al. 2002). Although the pharmacological activity of KTP resides principally in the $(+)-S$ enantiomer (eutomer), it is marketed mainly in the form of a racemic (rac-) mixture. The (-)- $R$ enantiomer of some profens undergo a unidirectional chiral inversion to the $(+)-S$ enantiomer via the formation of its acyl CoA thioester. In humans, the chiral inversion of $(-)-R$ to (+)-S-KTP is limited to approximately $10 \%$ (Rudy et al. 1998). It may be one of the reasons for small differences 
between pharmacokinetic parameters of KTP enantiomers, reported by most of the literature data. The data regarding pharmacokinetics of KTP are based mostly on the studies performed in healthy volunteers. Ishizaki et al. (1980) observed significant differences in $C_{\max }, t_{\max }, \mathrm{Cl}$ and $V_{\mathrm{d}}$ following oral, intramuscular and rectal administration of $100 \mathrm{mg}$ rac-KTP to healthy volunteers. The kinetics of the $(-)-R$-KTP were studied following the administration of both the racemate and the (-)- $R$ enantiomer to healthy volunteers. There were small $(<5 \%)$ differences between AUC of the enantiomers, and the elimination rate constant of (-)-R-KTP was gender dependent (Rudy et al. 1998). More recently, pharmacokinetic studies of KTP enantiomers in healthy volunteers involved administration of standard and sustained release tablets with rac-KTP (Główka 2002; Główka and Karaźniewicz 2004). Significant differences in the pharmacokinetic parameters of both formulations were observed, but not between (-)- $R$ and (+)-S enantiomers within one formulation (Główka 2002). Although KTP has a proven effectiveness in the treatment of arthritic diseases, data regarding pharmacokinetics of KTP enantiomers in patients with RA are limited. Skeith et al. (1993) examined the effect of dose, renal function and the presence of arthritis on the stereoselective kinetics of the drug. No significant differences in pharmacokinetic parameters were found between non-arthritic and arthritic subjects. Moreover, Foster et al. (1998) found no significant differences in KTP pharmacokinetics between young and elderly patients with arthritis. Park et al. (2001) observed differences in pharmacokinetics of racemic KTP in plasma and synovial fluids in arthritic patients at steady state after 100-mg oral doses. Although, pharmacokinetics of KTP enantiomers in patients with RA may be affected by impaired metabolism of the drug or co-administered medicines, there are no data regarding inter-individual variability of pharmacokinetic parameters of KTP enantiomers caused by these factors. Recent studies indicate that impaired metabolism of enantiomers of 2-APA derivatives may be caused by genetic polymorphism of drug-metabolizing enzymes, CYP2C8 and CYP2C9 (Garcia-Martin et al. 2004; Karaźniewicz-Łada et al. 2009). Although the main metabolic pathway of KTP enantiomers is direct glucuronidation, the drug is a substrate for CYP450 isoenzymes which are responsible for its hydroxylation (Rodrigues 2005). Currently, there are no literature data on the effect of genetic polymorphism of CYP450 enzymes on pharmacokinetics of KTP enantiomers.

The paper presents the results of pharmacokinetic studies of KTP enantiomers in patients with RA with reference to genetic polymorphism and long-term multidrug therapy. The outcomes may be helpful for improving therapy by settlement of individual KTP dosing for patients with RA.

\section{Materials and methods}

\subsection{Chemicals}

A racemic mixture of KTP, (+)-S-KTP (optical purity, o.p. 99.0\%), (+)-S-naproxen $[(+)-S$-NPX] (o.p. 98.0\%) and heptakis 2,3,6-tri-O-methyl- $\beta$-cyclodextrin (TM $\beta \mathrm{CD}$ ) was obtained from Sigma (St. Louis, MO, USA); $85 \%$ of orthophosphoric acid (P.O.Ch., Gliwice, Poland) and triethanolamine (Sigma-Aldrich Chemie, Steinheim, Germany) were of reagent grade. $\beta$-glucuronidase solution from Helix pomatia (containing $1,000-5,000 \mathrm{U} / \mathrm{ml}$ of sulfatase and $100,000 \mathrm{U} / \mathrm{ml}$ of $\beta$-glucuronidase) were from Sigma; $1.0 \mathrm{M}$ and $0.1 \mathrm{M} \mathrm{NaOH}$, water for HPCE (Agilent Technologies, Waldbronn, Germany), potassium dihydrogen phosphate (Xenon, Łódź, Poland) and disodium hydrogen phosphate anhydrous (Fluka, Buchs, Switzerland) were used.

\subsection{Equipment and CZE conditions}

Determination of KTP enantiomers was performed on an Agilent model ${ }^{3 \mathrm{D}} \mathrm{CE}$ apparatus (Agilent Technologies, Waldbronn, Germany) with UV detector set at $253 \mathrm{~nm}$. Extracted samples were automatically injected using hydrodynamic injection at the anode. The temperature of the capillary was maintained by a thermostatic system at $30^{\circ} \mathrm{C}$. The separation was performed in a fused silica capillary, $40 \mathrm{~cm} \times 50 \mu \mathrm{m}$ i.d., $31.5 \mathrm{~cm}$ to the detector. The apparatus was equipped with ChemStation software. All experiments were carried out at $25 \mathrm{kV}$ and $50 \times 5$ mbar s injection (10 $\mathrm{nL}$ injected volume). The enantiomers were determined using a $0.02 \mathrm{M}$ background electrolyte (BGE) containing $0.05 \mathrm{M} \mathrm{TM} \beta \mathrm{CD}$. BGE of $\mathrm{pH} 5$ was prepared as a mixture of appropriate volumes of aqueous $0.2 \mathrm{M}$ orthophosphoric acid and $0.2 \mathrm{M}$ triethanoloamine. The solution was passed through $0.45 \mu \mathrm{m}$ filter and degassed by ultrasound before insertion into the capillary.

\subsection{Determination of KTP enantiomers in plasma, synovial fluid and urine}

For determination of KTP enantiomers in human plasma, synovial fluid and urine, the above CZE method was used. Volumes of $0.5 \mathrm{~mL}$ of plasma or synovial fluid were spiked with $50 \mu \mathrm{L}$ of $20 \mathrm{mg} / \mathrm{L}(+)-S$-NPX solution as internal standard (IS). The resulting mixture was acidified with $0.2 \mathrm{~mL}$ of $1.0 \mathrm{M}$ orthophosphoric acid and extracted with $2 \mathrm{~mL}$ of dichloromethane. The mixture was shaken for $10 \mathrm{~min}$ at an amplitude of $1 \mathrm{~cm}$ and a frequency of 300 cycles $\min ^{-1}$, subsequently cooled at $4^{\circ} \mathrm{C}$ for $20 \mathrm{~min}$ and centrifuged for $5 \mathrm{~min}$ to attain proper separation of the two phases. The lower organic layer was transferred to glass 
tubes and evaporated to dryness at $40^{\circ} \mathrm{C}$ under a gentle nitrogen flow. To determine the total (free and conjugated with glucuronic acid) amounts of KTP enantiomers excreted in urine, $100 \mu \mathrm{L}$ of urine was mixed with $1 \mathrm{~mL}$ of phosphate buffer, $\mathrm{pH} 7.4$ and $5 \mu \mathrm{L}$ of $\beta$-glucuronidase. Then, the mixture was incubated at $37^{\circ} \mathrm{C}$ for $20 \mathrm{~h}$. Subsequently, the enzymatically treated urine samples were spiked with $50 \mu \mathrm{L}$ of the IS solution and extracted with dichloromethane according to the procedure described above. The dry residue was dissolved in $50 \mu \mathrm{L}$ of methanol and $150 \mu \mathrm{L}$ of demineralized water and injected into the silica capillary filled with BGE.

The CZE method, before use for the analysis of KTP enantiomers in biological fluids of RA patients, has been validated (Główka and Karaźniewicz-Łada 2008).

\subsection{Pharmacokinetic and genotyping analysis}

The investigations were approved by the Ethics Committee at Poznan University of Medical Sciences. Eleven patients with RA ( 8 female, 3 male) aged between 39 and 73 years (mean \pm SD: $50 \pm 10$ years) of weight $64 \pm 13 \mathrm{~kg}$ were included in this study. All subjects were white Polish individuals treated at the Poznan Rheumatology Center in Śrem. Inclusion criteria were: male or female; puncture was required because the presence of the exudative liquid handicapped the activity of the joint. Patients with RA also suffered from other diseases, such as hypertension (5 patients), osteoporosis (4 patients), diabetes (1 patient), ischemic heart disease (1 patient), chronic lymphocytic thyroiditis (1 patient) and knee joint inflammation (2 patients). Four patients suffered from more than one disease. Rheumatoid factor (RF) was determined in the plasma of nine subjects. All patients were fully informed of the nature of these studies, signed informed consent forms and could discontinue their participation at any time. Subjects received a single tablet of $100 \mathrm{mg}$ racemic KTP (Lek, Ljubljana, Slovenia). Patients were also receiving additional medicines due to their medical conditions (Table 1). None of these drugs or their metabolites were found to interfere with the analysis of KTP. Blood samples were collected immediately prior to administration of rac-KTP and at 2.0, 4.0 and $6.0 \mathrm{~h}$ postdrug administration; synovial fluid samples were taken at $4 \mathrm{~h}$ postdrug administration. Urine samples were also collected into separate containers over $24 \mathrm{~h}$ after administration. The volume of each urine sample was measured and after centrifugation kept frozen at $-20^{\circ} \mathrm{C}$ until required for analysis. Moreover, from eight patients blood samples were collected in EDTA blood tubes for the genotype analysis. The concentrations of KTP enantiomers in plasma were used for the calculation of pharmacokinetic parameters using onecompartmental analysis. The Topfit 2.0 software package (Heinzel et al. 1993) was used for the pharmacokinetic calculations. $\mathrm{AUC}_{0-\infty}$ was estimated by trapezoidal rule with extrapolation to infinity using $C_{\mathrm{n}} / k_{\mathrm{e}}$ where $C_{\mathrm{n}}$ was the last measurable concentration in plasma and $k_{\mathrm{e}}$ was the firstorder elimination rate constant. The maximum plasma concentration $\left(C_{\max }\right)$ and the time to reach $C_{\max }\left(t_{\max }\right)$ were

Table 1 Clinical characteristics of patients with rheumatoid arthritis

\begin{tabular}{|c|c|c|c|c|c|}
\hline Initials & Age & Sex & Weight $[\mathrm{kg}]$ & $\mathrm{RF}[\mathrm{IU} / \mathrm{ml}]$ & Medications administered simultaneously \\
\hline J.M. & 48 & M & 83 & 12 & $\begin{array}{l}\text { Amlodipine, azathioprine, diclofenac, methylprednisolone, } \\
\text { metoprolol, omeprazole, sulphasalazine }\end{array}$ \\
\hline G.P. & 40 & M & 86 & 12 & Sulphasalazine \\
\hline R.I. & 54 & $\mathrm{~F}$ & 58 & 0 & $\begin{array}{l}\text { Alendronate, methotrexate, methylprednisolone, } \\
\text { sulphasalazine, triamcinolone }\end{array}$ \\
\hline I.N. & 48 & $\mathrm{~F}$ & 56 & 12 & Diclofenac, methylprednisolone, omeprazole \\
\hline M.Z. & 39 & $\mathrm{~F}$ & 73 & 12 & Folic acid, methylprednisolone, omeprazole \\
\hline A.R. & 45 & $\mathrm{~F}$ & 48 & nd & Cyclosporine, folic acid, methotrexate, methylprednisolone \\
\hline M.B. & 52 & $\mathrm{~F}$ & 66 & 0 & $\begin{array}{l}\text { Folic acid, methotrexate, molsidomine, naproxen, } \\
\text { triamcinolone, trimetazidine dihydrochloride }\end{array}$ \\
\hline H.D. & 58 & $\mathrm{~F}$ & 56 & 96 & $\begin{array}{l}\text { Alendronate, diclofenac, insulin, methylprednisolone, } \\
\text { sulphasalazine, triamcinolone }\end{array}$ \\
\hline S.G. & 73 & $\mathrm{~F}$ & 58 & 384 & $\begin{array}{l}\text { Acetylsalicylic acid, amlodipine, diclofenac, folic acid, } \\
\text { isosorbide mononitrate, methotrexate, methylprednisolone, } \\
\text { metoprolol, omeprazole, triamcinolone }\end{array}$ \\
\hline H.B. & 58 & $\mathrm{~F}$ & 49 & nd & $\begin{array}{l}\text { Alendronate, azathioprine, diclofenac, lorazepam, } \\
\text { methylprednisolone }\end{array}$ \\
\hline R.P. & 41 & M & 76 & 24 & Bisoprolol, methotrexate, methylprednisolone, sulphasalazine \\
\hline Mean \pm SD & $50 \pm 10$ & & $64 \pm 13$ & & \\
\hline
\end{tabular}

nd no data 
calculated. Plasma drug clearance $(\mathrm{Cl} / F)$ was obtained dividing the dose $(D)$ of each enantiomer by $\mathrm{AUC}_{0-\infty}$. The volume of distribution $\left(V_{\mathrm{d}} / F\right)$ was estimated from $\mathrm{D} /\left(\mathrm{AUC}_{0-\infty} \cdot k_{\mathrm{e}}\right)$. Urinary amounts of KTP enantiomers (free + conjugated) were used to assess the percentage of eliminated dose of the drug.

Analysis of patients' genotype was performed using genomic DNA extracted from peripheral blood lymphocytes by the salting-out method. Then, polymerase chain reaction-restriction fragment length polymorphism (PCRRFLP) technique was used to analyze polymorphic variants of CYP2C8 and CYP2C9 (Karaźniewicz-Łada et al. 2009).

\section{Results and discussion}

\subsection{Genotyping for CYP2C8 and CYP2C9 alleles}

To investigate the genetic basis for the variability in KTP pharmacokinetics, CYP2C8 and CYP2C9 genotypes were analyzed in the studied population. Conditions for genotype analysis were previously applied for determination of mutant alleles responsible for impaired metabolism of ibuprofen (IBP) enantiomers in healthy volunteers (Karaźniewicz-Łada et al. 2009). In the studied group of eight patients with RA, no mutant alleles were detected and all these subjects appeared to possess a wild-type genotype.

\subsection{Pharmacokinetic parameters}

After administration of rac-KTP, concentration values of $(-)-R$-KTP in plasma, during the elimination phase were lower than those of the (+)-S enantiomer, but the differences were not statistically significant (Fig. 1). In previous studies performed on healthy volunteers (Główka 2002), the plasma levels of ( -$)-R$ enantiomer were higher than for

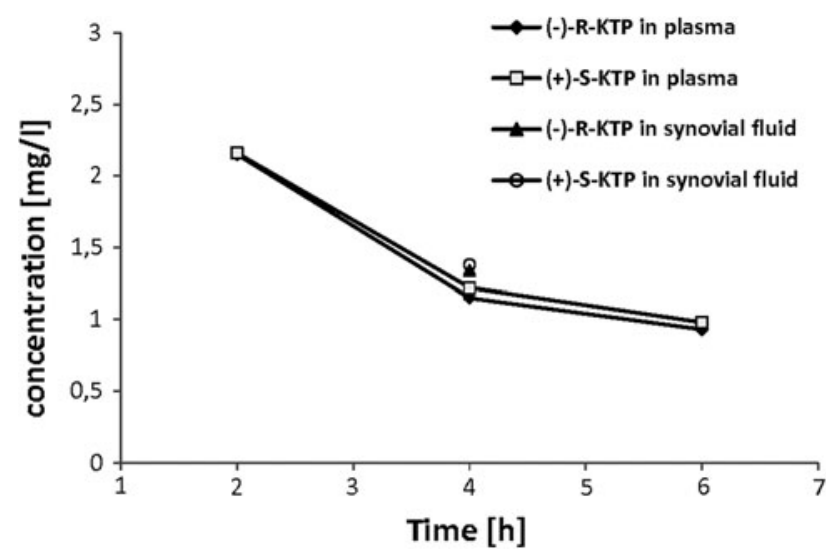

Fig. 1 Mean concentration of KTP enantiomers in plasma and synovial fluid versus time in patients with RA following administration of a single dose of $100 \mathrm{mg}$ rac-KTP
$(+)-S$-KTP, especially during the absorption and distribution phase, but concentration values during the elimination process were slightly higher for $(+)-S$-KTP as in RA patients. These data are consistent with unidirectional inversion of the (-)-R enantiomer to the $(+)-S$-KTP. However, according to literature, the chiral inversion of $(-)-R$ to (+)-S-KTP is limited to only $10 \%$ (Rudy et al. 1998). Concentrations of KTP enantiomers in synovial fluid at $4 \mathrm{~h}$ post-administration of the drug are presented in Fig. 2. The values were greater $[(-)-R=1.34 \pm 0.91 \mathrm{mg} / \mathrm{L} ;(+)-S=$ $1.38 \pm 0.91 \mathrm{mg} / \mathrm{L}]$ than in plasma $[(-)-R=1.15 \pm$ $0.95 \mathrm{mg} / \mathrm{L} ;(+)-S=1.22 \pm 0.95 \mathrm{mg} / \mathrm{L}]$, but the differences were not statistically significant (Fig. 1). It means that in the elimination phase, plasma and synovial levels are comparable. Then from plasma data of KTP enantiomers, we can predict their level in the synovial fluid. Different results were obtained in arthritic patients by Park et al. (2001), where the time course of the racemic KTP concentration in the synovial fluid was different from the plasma concentration time profile. The $\mathrm{AUC}_{0-\infty}$ was $11.89 \pm 5.00$ and $10.92 \pm 4.10 \mathrm{mg} \mathrm{h} / \mathrm{L}$ for the $(-)-R$ and (+)-S enantiomers, respectively, and was decreased in about $30 \%$ in comparison to the data obtained previously from healthy volunteers following administration of the same dose of rac-KTP (Table 2). One of the possible reasons for the lower bioavailability of KTP enantiomers could be the reduced gastrointestinal function, characteristic of elderly patients. The food should be also considered in these deliberations on decreasing of KTP bioavailability. Caillé et al. (1989) concluded that plasma concentrations of rac-KTP after administration of a single and multiple dose were affected by food, with a decrease of greater than $40 \%$ in bioavailability. Moreover, drugs co-administered with NSAIDs, such as the proton pump inhibitor-omeprazole, may affect absorption of the substance from the GI tract, and subsequently lower the fraction of the drug that reaches

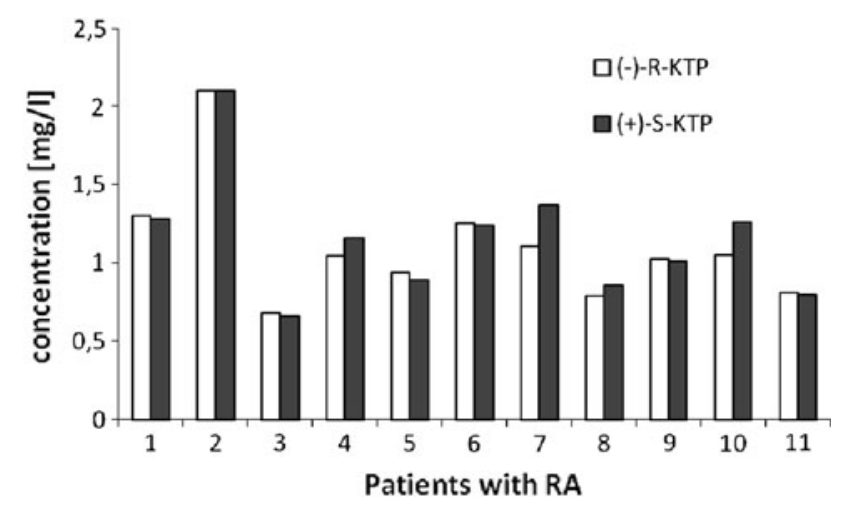

Fig. 2 Concentration of KTP enantiomers in synovial fluid in 11 patients with RA at $4 \mathrm{~h}$ following administration of $100 \mathrm{mg}$ rac-KTP 
Table 2 Pharmacokinetic parameters of KTP enantiomers after administration of $100 \mathrm{mg}$ rac-KTP to healthy volunteers (Główka 2002) and patients with RA

\begin{tabular}{|c|c|c|c|c|c|c|}
\hline \multirow[t]{2}{*}{ Parameters } & \multicolumn{3}{|l|}{$(-)-R-\mathrm{KTP}$} & \multicolumn{3}{|l|}{$(+)-S-\mathrm{KTP}$} \\
\hline & Patients with RA & $\begin{array}{l}\text { Healthy } \\
\text { volunteers }\end{array}$ & $\begin{array}{l}\text { ANOVA } \\
\alpha=0.05\end{array}$ & Patients with RA & $\begin{array}{l}\text { Healthy } \\
\text { volunteers }\end{array}$ & $\begin{array}{l}\text { ANOVA } \\
\alpha=0.05\end{array}$ \\
\hline$t_{0.5}(\mathrm{~h})$ & $1.66 \pm 0.43$ & $1.84 \pm 0.62$ & NS & $1.82 \pm 0.59$ & $2.10 \pm 0.73$ & NS \\
\hline $\operatorname{AUC}_{0-\infty}(\mu \mathrm{g} \mathrm{h} / \mathrm{ml})$ & $11.89 \pm 5.00$ & $17.16 \pm 2.30$ & $p=0.043$ & $10.92 \pm 4.10$ & $16.43 \pm 2.21$ & $p=0.014$ \\
\hline $\mathrm{Cl} / F(\mathrm{~L} / \mathrm{h})$ & $5.22 \pm 3.11$ & $2.96 \pm 0.38$ & NS & $5.19 \pm 2.01$ & $3.09 \pm 0.40$ & $p=0.038$ \\
\hline$V_{\mathrm{d}} / F(\mathrm{~L})$ & $12.88 \pm 8.44$ & $7.78 \pm 2.80$ & NS & $13.58 \pm 6.70$ & $9.14 \pm 3.43$ & NS \\
\hline MRT (h) & $2.70 \pm 0.82$ & $3.08 \pm 1.04$ & NS & $3.07 \pm 0.85$ & $3.18 \pm 1.08$ & NS \\
\hline
\end{tabular}

the systemic circulation. In the present studies, four patients were taking omeprazole along with KTP, but this did not affect $C_{\max }$ and AUC of the KTP enantiomers. The $t_{0.5}$ values of ( $(-)-R$ and ( + -) $S$ enantiomers of KTP did not differ significantly and they amounted to $1.66 \pm 0.43$ and $1.82 \pm 0.59 \mathrm{~h}$, respectively. The values are similar to literature data obtained following administration of $150 \mathrm{mg}$ rac-KTP to patients with RA, where elimination half-life was in the range of $2.55 \pm 0.48$ and $2.95 \pm 0.54 \mathrm{~h}$ for $(-)-R$ and (+)-S-KTP, respectively (Skeith et al. 1993). Also, no statistically significant differences were observed for other pharmacokinetic parameters of KTP enantiomers, such as $C_{\max }, \mathrm{Cl}, V_{\mathrm{d}}$ and MRT. It can due to the fact that chiral inversion of (-)- $R$ to $(+)-S$-KTP is negligible.

The differences between pharmacokinetic parameters obtained from healthy volunteers and RA patients exist, but only those for $\mathrm{AUC}_{0-\infty}$ of both KTP enantiomers and $\mathrm{Cl}$ of (+)-S-KTP were statistically significant (Table 2). The higher values of $\mathrm{Cl}$ and $V_{\mathrm{d}}$ in RA patients in comparison to healthy volunteers may be a result of changes in drug protein binding. The clearance of KTP, which is a drug with low hepatic extraction, is proportional to the unbound fraction of the drug. Thus, protein binding is an important determinant for pharmacokinetic parameters, such as $\mathrm{Cl}$ and $V_{\mathrm{d}}$. If the free fraction of KTP in blood is increased, the
$\mathrm{Cl}$ is also increased, resulting in smaller AUC. The elevations in the free fraction of drug may be caused by plasma protein displacement interaction, when the drug is concurrently administered with other drugs that bind with albumin. Plasma protein displacement is observed when NSAIDs are given with methotrexate, oral anticoagulants, antidiabetic agents and thyroid hormones (Mehanna 2003). Moreover, many NSAIDs such as naproxen, suprofen and fenoprofen have higher affinity in the binding to the protein than KTP (Bertucci 2001). The patients who participated in the study also were taking drugs, such as methotrexate, diclofenac, naproxen and acetylsalicylic acid, which have the potential possibility to interact with albumin as the displacers of KTP. Moreover, the free concentration of a drug can change because of hypoalbuminemia. According to the literature data, in RA patients the albumin level in plasma is decreased (Niwa et al. 1990).

The percentage of KTP (free + conjugated) eliminated with urine of patients with RA was in the range of 30-50\% of the administered dose (Fig. 3). These values show that the percentage of eliminated does of KTP enantiomers in some cases were greater than literature data where approximately $30 \%$ of the dose of KTP was recovered in urine of patients with RA (Sallustrio et al. 1988). However, this value is lower in comparison with the literature data
Fig. 3 Amounts of KTP enantiomers excreted with urine of patients with RA, presented as percentage of administered dose of each enantiomer. Dashed lines represent the levels of KTP excreted by healthy volunteers (* Ishizaki et al. 1980) or RA patients (** Sallustrio et al. 1988)

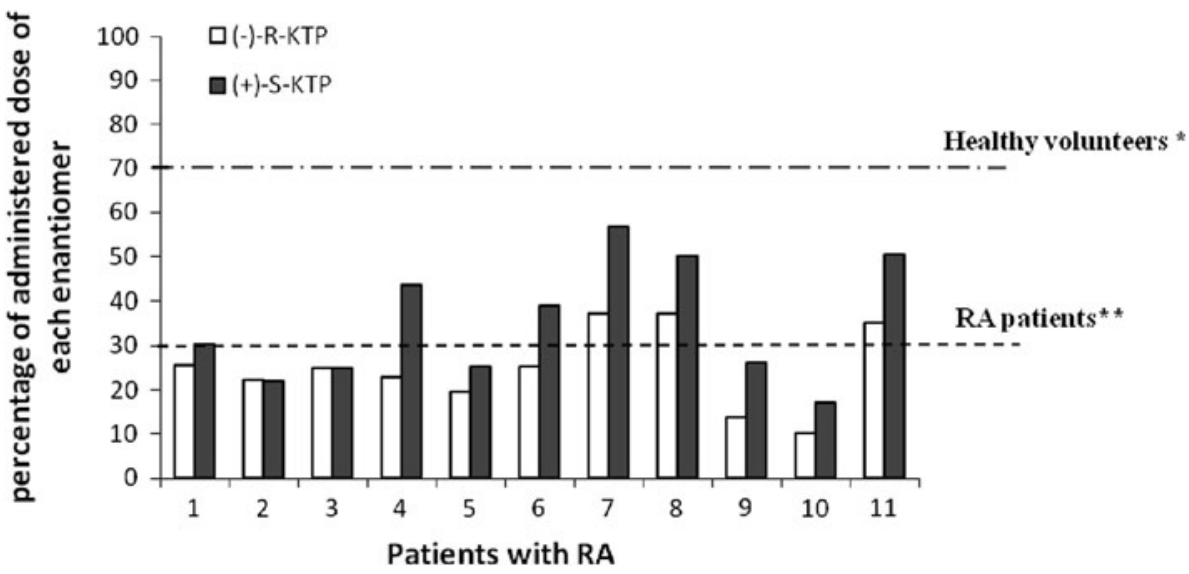




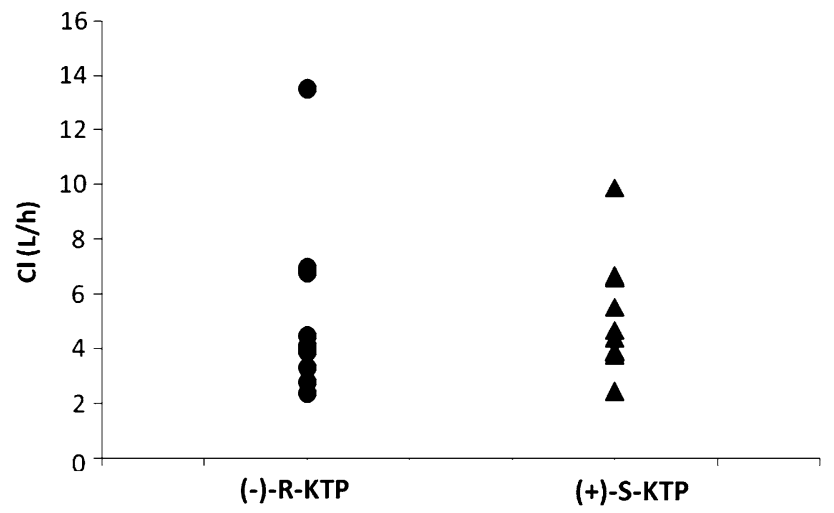

Fig. 4 Clearance of KTP enantiomers following administration of a tablet with $100 \mathrm{mg}$ rac-KTP to patients with RA

regarding healthy volunteers, where the cumulative amount of drug excreted with urine exceeded $63-75 \%$ of the dose (Ishizaki et al. 1980). This difference was also observed by Skeith et al. (1993). It was noticed that the mean percentage excretion of total KTP dose was up to $21 \%$ in the arthritic patients, whereas in the non-arthritic subjects up to $72 \%$ was excreted. The main reason for this can be the decreased bioavailability of KTP enantiomers observed in patients with RA. Moreover, reduced urinary excretion can be caused by enhanced enterohepatic circulation of conjugated KTP enantiomers in the elderly and subsequent biliary excretion (Sallustrio et al. 1988). Skeith et al. (1993) observed inter-subject variation of pharmacokinetics in the studied group of arthritic and non-arthritic patients, connected probably with age-related physiologic changes in the elderly. In our study, the group of patients with RA also exhibited a wide variability in the values of pharmacokinetic parameters, especially those characterizing phenotype $\left(\mathrm{Cl}, \mathrm{AUC}, \mathrm{t}_{0.5}\right)$. A wide range of clearance values observed in patients (Fig. 4) may suggest alteration in patients' genotype. However, eight subjects with a wildtype genotype and the values of $\mathrm{Cl}$ observed in three patients, in whom genotype was not determined, do not suggest the presence of any mutation. The main reason for inter-individual variability of pharmacokinetics in the studied group of patients with RA seems to be physiological function of the organs responsible for metabolism and elimination of the drug, which may be changed. Moreover, the influence of co-administered drugs on the plasma protein binding of KTP enantiomers cannot be ruled out.

\section{Conclusions}

We investigated the pharmacokinetics of KTP enantiomers under clinical conditions. To our knowledge, for the first time chiral pharmacokinetics of KTP has been estimated taking into consideration the genotype of RA patients. Our results confirmed that pharmacokinetic data of healthy volunteers, especially AUC, cannot be sufficient to predict the therapeutic effect of the chiral drug in RA patients. We conclude that inter-individual variability in pharmacokinetics of KTP enantiomers in patients with RA cannot be explained by genetic polymorphism of CYP450 enzymes. Because of decreased AUC in RA patients, during selection of individual therapy to the patients, the effect of co-administered drugs, type of pharmaceutical formulations and physiological changes related to the age of the patients and food should be taken into consideration.

Acknowledgments This work was supported by the Poznan University of Medical Sciences [Grant nr 501-01-3306413-04982].

Open Access This article is distributed under the terms of the Creative Commons Attribution Noncommercial License which permits any noncommercial use, distribution, and reproduction in any medium, provided the original author(s) and source are credited.

\section{References}

Baek SJ, Wilson LC, Lee CH, Eling TE (2002) Dual function of nonsteroidal anti-inflammatory drugs (NSAIDs): inhibition of cyclooxygenase and induction of NSAID-activated gene. J Pharmacol Exp Ther 301:1126-1131

Bertucci C (2001) Enantioselective inhibition of the binding of racprofens to human serum albumin induced by lithocholate. Chirality 13:372-378

Caillé G, du Souich P, Besner JG, Gervais P, Vezina M (1989) Effects of food and sucralfate on the pharmacokinetics of naproxen and ketoprofen in humans. Am J Med 86:38-44

Foster RT, Jamali F, Russell AS, Alballa SR (1998) Pharmacokinetics of ketoprofen enantiomers in young and elderly arthritic patients following single and multiple doses. J Pharm Sci 77:191-195

Garcia-Martin E, Martinez C, Tabares B, Frias J, Agundez JAG (2004) Interindividual variability in ibuprofen pharmacokinetics is related to interaction of cytochrome P450 2C8 and 2C9 amino acid polymorphisms. Clin Pharmacol Ther 76:119-127

Główka FK (2002) Determination of ketoprofen enantiomers in human serum by capillary zone electrophoresis. Man pharmacokinetic studies after administration of rac-ketoprofen tablets. J Pharm Biomed Anal 30:1035-1045

Główka FK, Karaźniewicz M (2004) High performance capillary electrophoresis for determination of the enantiomers of 2-arylpropionic acid derivatives in human serum. Pharmacokinetic studies of ketoprofen enantiomers following administration of standard and sustained release tablets. J Pharm Biomed Anal 35:807-816

Główka FK, Karaźniewicz-Łada M (2008) CE determination of ketoprofen enantiomers in clinical samples of plasma, synovial fluid and urine. Chromatographia 67:S97-S105

Heinzel G, Woloszczak R, Thomann P (1993) Pharmacokinetic and pharmacodynamics data analysis system for the PC. Gustav Fischer, Stuttgard

Ishizaki T, Sasaki T, Suganuma T, Horai Y, Chiba K, Watanabe M, Asuke W, Hoshi H (1980) Pharmacokinetics of ketoprofen following single oral, intramuscular and rectal doses and after repeated oral administration. Eur J Clin Pharmacol 18:407-414

Karaźniewicz-Łada M, Łuczak M, Główka F (2009) Pharmacokinetic studies of enantiomers of ibuprofen and its chiral metabolites in 
humans with different variants of genes coding CYP2C8 and CYP2C9 isoenzymes. Xenobiotica 39:476-485

Mehanna AS (2003) NSAIDs: chemistry and pharmacological actions. Am J Pharm Edu 67:1-7

Niwa Y, Iio A, Niwa G, Sakane T, Tsunematsu T, Kanoh T (1990) Serum albumin metabolism in rheumatic diseases: relationship to corticosteroids and peptic ulcer. J Clin Lab Immunol 31:11-16

Park JY, Sohn JH, Yoon YR, Shon JH, Cha IJ, Seo SS, Choi JS, Shin JG (2001) Disposition kinetics of ketoprofen into synovial fluid following systemic administration: population pharmacokinetic analysis. J Korean Soc Clin Pharmacol Ther 9:97-107

Rodrigues AD (2005) Impact of CYP2C9 genotype on pharmacokinetics: are all cyclooxygenase inhibitors the same? Drug Metabol Disp 33:1567-1575
Rudy AC, Liu Y, Brater C, Hall SD (1998) Stereoselective pharmacokinetics and inversion of (R)-ketoprofen in healthy volunteers. J Clin Pharmacol 38:3-10

Sallustrio BC, Purdie YJ, Whitehead AG, Ahern MJ, Meffin PJ (1988) The disposition of ketoprofen in man. $\mathrm{Br} \mathrm{J}$ Clin Pharmacol 26:765-770

Skeith KJ, Russell AS, Jamali F (1993) Ketoprofen pharmacokinetics in the elderly: influence of rheumatic disease, renal function and dose. J Clin Pharmacol 33:1052-1059 